\section{Subscriptions}

International Psychiatry is published four times a year.

Subscription: $f 15.00$ per annum.

For subscription enquiries please contact: Publications, Royal College of Psychiatrists, 17 Belgrave Square, London SW $1 X$ 8PG.

\section{Editor}

Prof. Hamid Ghodse

\section{Editorial board}

Dr JOHn Hen derson

Mr Dave Jago

Dr N ASSER LOZA

Dr Brian Martin dale

Dr Shekhar Saxen a

Prof. David SkUSe

Design (c) The Royal College of Psychiatrists 2004.

For copyright enquiries, please contact the Royal College of Psychiatrists.

All rights reserved. No part of this publication may be reprinted or reproduced or utilised in any form or by any electronic, mechanical or other means, now known or hereafter invented, including photocopying and recording, or in any information storage or retrieval system, without permission in writing from the publishers.

The views presented in this publication do not necessarily reflect those of the Royal College of Psychiatrists, and the publishers are not responsible

for any error of omission or fact.

The Royal College of Psychiatrists is a registered charity (no. 228636)

Printed in the UK by Henry Ling Limited at the Dorset Press, Dorchester DT1 1HD. therapeutic options, including the expected benefits and risks. The clinician- patient interaction involves responsibilities on the part of both, the extent of which is influenced by the culture of the country in question. In an age of wider access to health-related information, of 'concordance' and of joint decision making, the patient is seen as an increasingly important contributor to the entire therapeutic process and it is hoped that this 'therapeutic alliance' will improve compliance with treatment (Ghodse \& Khan, 1988; International N arcotics C ontrol Board, 2001).

In the midst of concern about the excessive use of psychotropic drugs, it is easy to ignore or forget the important facts about their therapeutic usefulness. However, the scientific evaluation of a drug should not be influenced by attitudes and value judgements, and psychotropic drugs should be assessed using the same tests and standards that are applied to non-psychotropic drugs. $W$ ithin this context it is important to remember that a lack of appropriate drugs deprives patients of their fundamental right of relief from suffering. At the same time, excessive use and over-medication leads to suffering of a different kind. The problem is that there is no universal consumption standard for psychotropic medication and no country or even region can be held up as an example of best practice.

The prescription of psychotropic medicines may be inappropriate if it is: uninformed; inconsistent or lax; knowingly done for misuse of the drug by the patient; for selfadministration. The underlying causes of such behaviour appear to be: inadequate training; shortage of information; lenient or lax attitudes; lack of sense of professional responsibility; unethical behaviour; personal drug addiction; criminality or corruption (G hodse \& Khan, 1988).

Psychiatrists can and should play an important role in educating doctors and other health care professionals as well as the public at large to achieve a culture of rational prescribing of psychotropic medicines. However, there is a wide range of policy makers, including government, health authorities, universities, postgraduate colleges, medical professional organisations and the pharmaceutical industry, all of which have an important influence on the education of health care professionals and so must also acknow ledge and implement their collective responsibilities in this area.

\section{References}

Fombonne, E., Mousson, F., Dassonville, B., et al (1989) A study of prescriptions for psychotropic drugs at a French psychiatric hospital. Revue Epidemologique Santé Publique, 37, 29-36.

Ghodse, A. H. (2003) Pain, anxiety and insomnia - a global perspective on the relief of suffering. Comparative review. British Journal of Psychiatry, 183, 15-21.

Ghodse, A. H. \& Khan, I. (1988) Psychoactive Drugs: Improving Prescribing Practices. Geneva: World Health $O$ rganization. International Narcotics Control Board (2001) Report of the International Narcotics Control Board for 2000 (E/IN CB/2000/ 1). $\mathrm{N}$ ew York: U nited $\mathrm{N}$ ations.

International N arcotics Control Board (2004) Psychotropic Drugs: Statistics for 2002. Assessment of Annual Medical and Scientific Requirements for Substances in Schedules II, III and IV (E/IN CB/2003/3). N ew York: United N ations.

\title{
Patient satisfaction with psychiatric care
}

\author{
David Skuse
}

Behavioural and Brain Sciences Unit, Institute of Child Health, London WC1 1EH, UK, email d.skuse@ich.ucl.ac.uk

e are enjoined nowadays to be ever more cognisant of the views of patients about the care they receive, in all forms of health service. From the point of view of psychiatry, there is a small but growing literature on this subject and we have three opinions from around the world in this issue. First, Australian colleagues from psychiatric nursing (Brenda $\mathrm{H}$ appell and Monica Summers) surveyed patients with mental health problems who attended an accident and emergency department. 0 ne important issue, which is reflected in many such departments around the world, is the length of time spent waiting for an assessment. Despite the fact that a triage process was available, which presumably did increase efficiency, the wait was too long for many clients, who left before being seen. (Most had attended after self-harming behaviour.)

A second article, from the U nited States, also from colleagues in psychiatric nursing (Patricia $\mathrm{H}$ oward et al) considers patient satisfaction with the quality of service received, and with treatment outcomes, in public sector psychiatric hospitals. Increasingly, the quality of care provided is being measured, in part, by how satisfied patients are with it. We anticipate these considerations will so on motivate care widely in the developed world. N oting that the majority of patients in this survey had been involuntarily confined, it is fascinating to learn what they felt had been the greatest sources of satisfaction during their confinement (mainly the opportunities to talk to other patients and to staff). The sources of dissatisfaction appear to be related to a failure of staff to listen sufficiently carefully to the needs of the patients.

Finally, we have a survey from the Swedish health care system. $H$ åkan Johansson po ints out that there is a structural problem with the very idea of measuring satisfaction. 0 utcome measures vary from survey to survey, and there is no clear relationship between satisfaction with care and treatment outcomes. The style of this survey was quite different to that of the previous two, for 
it was essentially qualitative in character. The patients who were most satisfied with the care they had received were those who were able to form a warm, empathic relationship with staff, whether this was in an out-patient or an in-patient setting. There was a fascinating dissonance between the perceptions of patients, for whom time was elastic and who wished to have more contact with staff, and the availability of those staff.
These three reviews, covering aspects of care from attendance at an emergency clinic to involuntary admission, recognise that there are many sources of patients' satisfaction with their care, especially in the domain of patient-staff relationships. They also bring to our attention the continuing need to consider the most appropriate structural arrangements for the provision of psychiatric care.

\title{
Satisfaction with psychiatric services in the emergency department
}

\author{
Brenda Happell ${ }^{1}$ and Monica Summers ${ }^{2}$
}

${ }^{1}$ Associate Professor and Director, Centre for Psychiatric Nursing Research and Practice, School of Postgraduate Nursing, University of Melbourne, Level 1, 723 Swanston Street, Carlton, Victoria 3053, Australia, email bhappell@unimelb.edu.au

2Unit Manager, Victorian Institute of Forensic Mental Health (Forensicare), Fairfield, Victoria, Australia

\begin{abstract}
he move to provide psychiatric services within the general health care system has resulted in emergency departments becoming the means of access to acute psychiatric care in Australia (Gillette \& Bucknell, 1996). Triage within the emergency departments ensures that patients are reviewed and treated in a timely manner, in accordance with the urgency of the presenting problem. The $\mathrm{N}$ ational Triage Scale was developed as a clinical tool for this purpose for use in Australia and $\mathrm{N}$ ew Zealand (Australasian College for Emergency Medicine, 1994). However, this scale tends to attach lower priority to psychiatric issues (Smart et al, 1998).

The implications for the triage of psychiatric clients are significant. The available research suggests that nurses do not consider themselves to have the skills and experience or the appropriate facilities to meet the needs of psychiatric clients (Gillette \& Bucknell, 1996; Putman, 1998; Bailey, 1998; Crowley, 2000). This has reportedly resulted in increased waiting times, with the result that many clients leave the emergency department before being seen (Gillette \& Bucknell, 1996; Bailey, 1998; Putman, 1998, Smart et al, 1998; Crowley, 2000).

A comprehensive evaluation of psychiatric clients' perceptions of and satisfaction with the services offered by emergency departments has not been conducted in Australia to date. This information is crucial for future service planning. The current research project was initiated in order to determine the level of satisfaction with the services provided and to identify areas where further development or improvement is required.
\end{abstract}

\section{Method}

The results presented are based upon secondary analysis of data collected as part of a study conducted in the emergency department. The primary study focused on clients presenting following an episo de of deliberate selfharm; however, contact details were collected for all clients assessed by psychiatric service staff in the emergency department over 6 months. The complete sample has been included in this study.

Emergency psychiatric staff assessed a total of 276 clients during the 6 months of the study. Telephone contact was made with 180 clients within 3 weeks of their presentation at the emergency department, following consultation with the psychiatric team. $\mathrm{N}$ inety-five clients could not be contacted and one declined to participate in the interview.

Telephone interviews were conducted by a registered psychologist (who had not interviewed the client at the time of presentation) using a semi-structured interview schedule designed to elicit information on what was helpful and what was not helpful, and to encourage feedback that could improve the service provided by the emergency department. Data were coded and entered into a Microsoft Excel database. Data were primarily analysed to produce descriptive statistics.

\section{Results}

The diagnosis was recorded for all 276 of the psychiatric clients. The most frequent causes of presentation were adjustment disorder $(22 \%)$, depression (21\%), psychotic disorder (20\%), personality disorder (16\%) and
The move to provide psychiatric services within the general health care system has resulted in emergency departments becoming the means of access to acute psychiatric care in Australia. 